\title{
O Programa Bolsa Família tem efeito pró-natalista? Uma análise da fecundidade nos Censos 2000 e 2010 e das perspectivas a partir do Brasil Carinhoso
}




\section{Resumo}

\section{APESAR DA ACENTUADA OUUEDA DE FECUNDIDADE VERIFICADA \\ NO BRASIL NOS ÚLTIMOS OUARENTA ANOS, PROCESSO ESTE OUE \\ TROUXE A TAXA DE FECUNDIDADE TOTAL PARA ABAIXO DO NÍVEL DE \\ REPOSIÇÃO NESTE INÍCIO DE SÉCULO XXI, PERSISTE NO IMAGINÁRIO \\ COLETIVO A IMPRESSÃO DE OUE OS POBRES TÊM MUITOS FILHOS, E \\ OUE OS PROGRAMAS GOVERNAMENTAIS}

DE TRANSFERÊNCIA DE RENDA TENDERIAM

A ESTIMULAR A FECUNDIDADE ENTRE A POPULAÇÃO POBRE OU EXTREMAMENTE POBRE.

\section{ESTE TRABALHO PROCURA ENFRENTAR ESTA OUESTÃO² À LUZ DA LITERATURA} NACIONAL E INTERNACIONAL, BEM COMO ANALISAR AS TENDÊNCIAS REVELADAS PELOS MICRODADOS DA AMOSTRA DO CENSO DE 2010, RECENTEMENTE DIVULGADAS PELA FUNDAÇÃO INSTITUTO BRASILEIRO de Geografia e Estatística (IBGE).

\begin{abstract}
IN SPITE OF THE PRONOUNCED FERTILITY DECREASE PERCEIVED IN BRAZIL DURING THE LAST FORTY YEARS, A PROCESS WHICH BROUGHT THE TOTAL FERTILITY RATE BELOW REPLACEMENT LEVEL IN THE BEGINNING OF THE TWENTY-FIRST CENTURY, IN THE COLLECTIVE IMAGINATION STILL REMAINS THE IMPRESSION THAT POOR PEOPLE HAVE MANY CHILDREN, AND THAT THE GOVERNMENTAL INCOME TRANSFERENCE PROGRAMS WOULD HAVE THE EFFECT OF STIMULATING FERTILITY AMONG THE POOR OR EXTREMELY POOR POPULATION.
\end{abstract}

THE PRESENT PAPER TRIES TO FACE THIS QUESTION UNDER THE VIEW OF NATIONAL AND INTERNATIONAL LITERATURE, AS WELL AS TO ANALYSE THE TRENDS SHOWN BY MICRODATA OF THE SAMPLE OF THE 2010 CENSUS, RECENTLY PUblished bY the Foundation BRAzILIAN GeOGraphy and Statistics INSTITUte (IBGE).

20 autor deste artigo definitivamente não se alinha entre os entusiastas dos programas de transferência de renda como estratégia de superação da extrema pobreza. Pelo contrário, tem severas críticas em relação a eles, tanto de mérito quanto no que concerne à eficácia dos mecanismos de seleção dos beneficiários, de fixação do valor dos benefícios e de controle do cumprimento das condicionalidades. Entretanto, o presente trabalho aborda apenas e tão somente os aspectos ligados ao tema da fecundidade, que o autor entende merecer uma abordagem desvinculada dos demais.

\section{PALAVRAS-CHAVE:}

Programa Bolsa Família; Fecundidade; Efeito Natalista

Revista Brasileira de Monitoramento e Avaliação | Número 3 | Janeiro-Junho de 2012

O Programa Bolsa Família tem efeito pro-natalista? Uma análise da fecundidade nos Censos 2000 e 2010 e das perspectivas a partir do Brasil Carinhoso. 
1. Considerações sobre as tendências da fecundidade nas últimas décadas nos países desenvolvidos e no Brasil

Encontra-se razoavelmente pacificada na literatura internacional a chamada Teoria da Transição Demográfica ${ }^{3}$, segundo a qual todas as sociedades experimentaram ou experimentarão uma sequência de transformações em seus padrões de mortalidade e fecundidade, começando pela redução da primeira, que leva a uma aceleração temporária das taxas de crescimento vegetativo, posteriormente reequilibradas pela queda das taxas de fecundidade até níveis próximos ao de reposição (2,1 filhos por mulher).

Nos países ditos desenvolvidos, este processo levou aproximadamente um século, começando na segunda metade do século $X I X^{4}$. A lentidão do processo deveu-se, de um lado, à demora na propagação das inovações científicas e melhorias sanitárias responsáveis pelo declínio da mortalidade, sobretudo a infantil, e, de outro lado, ao longo período de aprendizado do controle da fecundidade pelos casais 5 .

A ocorrência de novas quedas de fecundidade, desta vez para bem abaixo do nível de reposição nos países desenvolvidos a partir da década de 1970, colocou em xeque a Teoria da Transição Demográfica enquanto matriz explicativa de um processo de reequilíbrio populacional. A partir daí, as opiniões dos demógrafos dividem-se quanto às explicações para o processo verificado e quanto à validade das projeções para o futuro. As explicações in- da sociologia e da antropologia. Discute-se se haveria uma Segunda Transição Demográfica explicável por elementos diferentes da primeira, ou simplesmente o aprofundamento do mesmo processo, agora facilitado pelo acesso à pílula anticoncepcional e pela virtual universalização do acesso à informação.

Também são relevantes os debates a respeito dos efeitos da baixa fecundidade sobre o envelhecimento das populações e sobre os limites da política de imigração enquanto supridora do déficit de população economicamente ativa?.

Em face das implicações econômicas e geopolíticas da prolongada queda da fecundidade, sobretudo nos países europeus, a discussão sobre a conveniência da intervenção estatal no processo e da capacidade prática dos países para isto vem dominando a agenda da demografia europeia já há várias décadas.

No caso brasileiro, o processo de declínio da fecundidade foi postergado por uma série de razões, vindo a iniciar-se somente na década de $1960^{\circ}$. A coincidência temporal entre o surgimento e a institucionalização da demanda pelo controle privado da fecundidade ${ }^{10} \mathrm{e}$ a introdução da pílula anticoncepcional conferiram inusitada rapidez ao processo de queda da fecundidade, que atingiu níveis próximos do de reposição (2,1 filhos por mulher) já na 
virada do século e inferiores a este no final da primeira década do século $X X \mid$.

O processo de transição da fecundidade brasileira na segunda metade do século $X X$ foi mapeado por Merrick e Berquó (1983), e por Berquó e Cavenaghi (2004). Em ambos os trabalhos, fica patente a irradiação da tendência de queda dos estados mais desenvolvidos para os menos e das mulheres mais ricas e escolarizadas para as menos.
As últimas projeções divulgadas pelo IBGE, em 2008, já apontam para a reversão da tendência de crescimento da população brasileira nas próximas décadas ${ }^{11}$.

Desta forma, pode-se especular que o Brasil esteja no limiar de um processo demográfico no qual a resposta desejável à indagação sobre possíveis efeitos pró-natalistas de determinadas políticas públicas deixe de ser não e passe a ser sim.

3 Segundo Patarra (1973), a Teoria da Transição Demográfica foi proposta originalmente por Warren Thompson em 1929. sendo posteriormente revisitada e popularizada por Frank Notenstein em 1945.

4 Therborn (2006) realiza um interessante esforço de datação do processo nas várias regiões da Europa, América do Norte e Ásia

5 Therborn (2006) descreve sucintamente o processo de substituição dos mecanismos de regulação da fecundidade pela via do adiamento dos casamentos pelo controle da fecundidade marital, ainda com métodos primitivos e pouco eficientes.

6 A idéia de uma Segunda Transição, com motivações e características distintas da Primeira, foi construída a partir da provocação de Ariès (1980). Seus principais formuladores e defensores são Lesthaeghe e Surkyn (2004), e seus maiores críticos são Coleman (2004) e Cliquet (1991).

7 Coleman (2004) explora os efeitos da imigração substitutiva de população nos países desenvolvidos.

8 Ver, a respeito, Bourgeois-Pichat (1986).

9 Paiva (1984b) procura analisar a tendência da fecundidade no Brasil do final do século XIX até 1970, levantando hipóteses tanto para a manutenção de níveis elevados até a década de 1960 quanto para o rápido declínio iniciado no período subsequente.

10 Faria (1989) propõe um quadro explicativo bastante convincente para a institucionalização da demanda pelo controle da fecundidade no Brasil, mesmo na ausência de ações deliberadas do governo com este objetivo.

11 Ver Carvalho (2001).

Revista Brasileira de Monitoramento e Avaliação | Número 3 | Janeiro-Junho de 2012

O Programa Bolsa Família tem efeito pro-natalista? Uma análise da fecundidade nos Censos 2000 e 2010 e das perspectivas a partir do Brasil Carinhoso. 


\section{Considerações sobre as correlações entre fecundidade, renda e escolaridade}

Nas décadas de 1960 e 1970, houve diversas iniciativas com origem em instituições privadas e públicas sediadas em países desenvolvidos, especialmente nos Estados Unidos ${ }^{12}$, no sentido de exportar para os países em desenvolvimento ou subdesenvolvidos as virtudes de um padrão de fecundidade similar ao existente nos países desenvolvidos na época, qual seja próximo do nível de reposição.

Um dos argumentos centrais deste processo de convencimento foi a exploração das correlações negativas entre fecundidade e renda e entre fecundidade e educação, especialmente feminina ${ }^{13}$. Tais correlações foram largamente demonstradas por estudos conduzidos por instituições internacionais, tanto no plano macro, nacional ou regional quanto no plano micro, de âmbito familiar. Considerando a forte correlação entre renda, escolaridade e acesso à informação, é redundante procurar-se relacionar individualmente cada uma destas variáveis com a fecundidade.

O outro grande pilar da discussão sobre a fecundidade nos países desenvolvidos vem a ser o da igualdade de gêneros. Mac Donald (1997) explora o tema do descompasso das diversas agências na migração do modelo "homem provedor" para o modelo da igualdade de gêneros. Enquanto as instituições de educação foram pioneiras nesta migração, seguidas pelo mercado de trabalho, os modelos familiares predominantes ainda reservam às mulheres a responsabilidade quase total pela criação dos filhos. Segundo argumenta o autor, quanto maior o descompasso nesta migração, maior a tendência de redução da fecundidade.

No caso brasileiro, as investigações realizadas a partir da década de setenta corroboraram a percepção do senso comum de que as mulheres mais pobres e menos escolarizadas tinham mais filhos que as mais ricas e escolarizadas. Esta coincidência favoreceu imensamente a receptividade da tese da conveniência da limitação da natalidade entre os mais pobres. Esta "conveniência" continua fortemente presente no imaginário coletivo de amplos setores da sociedade brasileira, sobretudo importantes formadores de opinião, especialmente jornalistas.

A despeito da prevalência da preocupação com a explosão demográfica entre os mais pobres por parte de atores importantes no processo político, todos os indicadores disponíveis revelam que o hiato de comportamento vem se reduzindo rapidamente no Brasil, seja pelo corte regional, seja pelos cortes de renda e escolaridade. A clivagem que persiste entre ricas e pobres desloca-se progressivamente da quantidade dos filhos para o momento de tê-los. Enquanto as mais ricas e escolarizadas vêm adiando continuamente a maternidade, seguindo o padrão europeu, as mais pobres e menos escolarizadas encerram cada vez mais cedo a fase reprodutiva. Não obstante esta tendência geral, verificou-se ao longo da pri- 
meira década do século XXI uma importante redução da fecundidade no grupo etário de 15 a 19 anos, o que indica o sucesso de programas de difusão de informação sobre sexualidade e reprodução, bem como de distribuição gratuita de pílulas anticoncepcionais e preservativos por parte do Sistema Único de Saúde.

\section{Análise da fecundidade nos Censos 2000 e 2010}

Seguindo tendência histórica de queda desde os anos 1960, a fecundidade da mulher brasileira caiu para níveis abaixo do patamar de reposição, como revelam os dados do Censo Demográfico 2010. Entre 2000 e 2010, а Таха de Fecundidade Total no Brasil caiu de 2,35 para 1,90 filhos por mulher.

Este trabalho constitui um primeiro exercício de verificação das tendências da fecundidade segundo as Grandes Regiões, as faixas de renda domiciliar per capita e a percepção de benefícios do Programa Bolsa Família (PBF) e de Erradicação do Trabalho Infantil (PETI).

\subsection{CONSIDERAÇÕES METODOLÓGICAS}

Uma vez que o IBGE já divulgou as taxas agregadas tanto para o Censo de 2000 quanto para o de 2010, é imperativo que a metodologia adotada proporcione resultados idênticos, ou pelo menos bastante semelhantes, aos já divulgados.

A metodologia adotada para estimação das taxas de fecundidade total será indireta, qual seja o Método de Brass - Variante Trussell.

Este método baseia-se em três perguntas básicas aplicadas a todas as mulheres entre $15 \mathrm{e}$ 49 anos na amostra do Censo. São elas: a idade em anos completos, a existência ou não de filho nascido vivo nos doze meses imediatamente anteriores à data de referência e o número total de filhos nascidos vivos tidos até o dia imediatamente anterior à data de referência.

A relação entre o número de filhos nascidos vivos nos doze meses imediatamente anteriores à data de referência e o número de

Revista Brasileira de Monitoramento e Avaliação | Número 3 | Janeiro-Junho de 2012 
mulheres em cada grupo etário quinquenal resulta na proxy da fecundidade corrente. O Método de Brass-Trussell promove o cruzamento deste indicador com o número total de filhos nascidos vivos por mulher, também por grupo quinquenal, mediante o uso de séries polinomiais, com os objetivos de corrigir erros de declaração do primeiro indicador e construir uma proxy da Taxa de Fecundidade Total (TFT), que vem a ser a quantidade esperada de filhos por mulher ao final da sua vida reprodutiva, convencionalmente aos 50 anos.

\subsection{AFERIÇÃO DA PRECISÃO METODOLÓGICA}

Partindo-se dos microdados da amostra, são selecionadas as mulheres com idade entre 15 e 49 anos completos, moradoras de do- micílios particulares permanentes, e tabuladas as respostas às três perguntas mencionadas no item 1. Isto implica desconsiderar os filhos nascidos vivos tidos por mulheres abaixo de 15 e acima de 49 anos, cuja ocorrência é residual, além de excluir da base situações especiais como presídios femininos.

Para fins de verificação da precisão metodológica, inicia-se por comparar os resultados obtidos a partir do processamento dos microdados dos Censos 2000 e 2010 com os divulgados pelo IBGE, tanto para o País quanto para as cinco Grandes Regiões.

Conforme se observa no Gráfico 1, os valores encontrados são muito semelhantes aos divulgados pelo IBGE.

GRÁFICO 1: TAXAS DE FECUNDIDADE TOTAL.

ESTIMATIVAS ELABORADAS X DADOS DIVULGADOS PELO IBGE - BRASIL, 2010

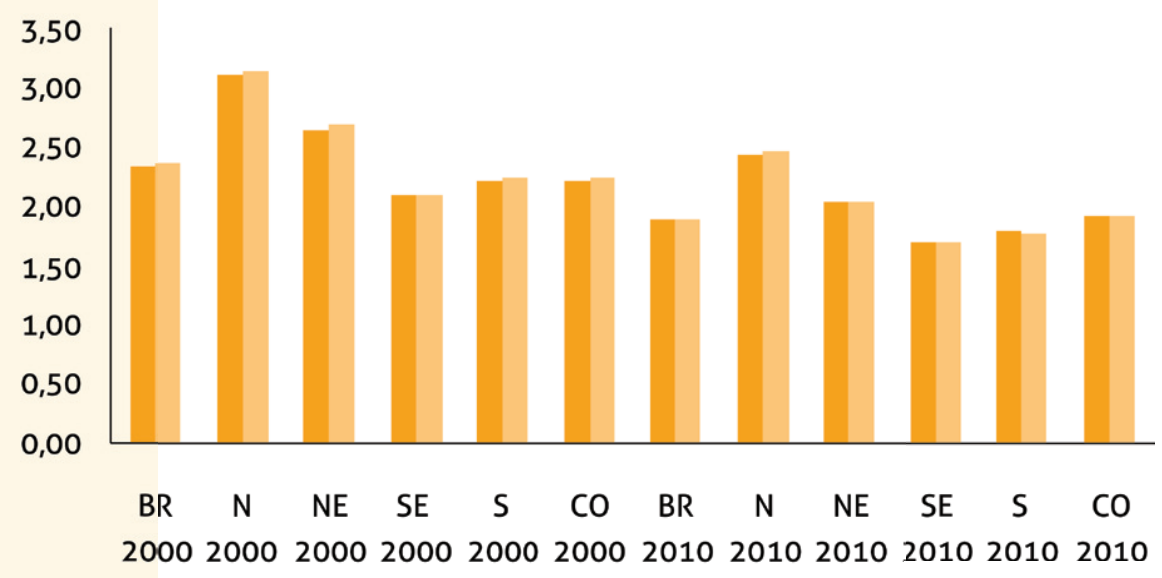

\section{Estimativa Divulgado IBGE}


A Tabela 1 apresenta os dados que originam o Gráfico 1, além de explicitar as variações da TFT, em número de filhos por mulher e percentual do valor de 2000.

TABELA 1: COMPARAÇÃO ENTRE OS RESULTADOS OBTIDOS E OS DIVULGADOS PELO IBGE

\begin{tabular}{|l|l|l|l|c}
$\begin{array}{c}\text { Região- } \\
\text { Ano }\end{array}$ & Estimativas & IBGE & $\begin{array}{c}\text { Filhos/ } \\
\text { Mulher }\end{array}$ & (\%) \\
\hline BR 2000 & 2,35 & 2,38 & $-0,03$ & $-1,14 \%$ \\
N 2000 & 3,12 & 3,16 & $-0,04$ & $-1,22 \%$ \\
NE 2000 & 2,65 & 2,69 & $-0,04$ & $-1,57 \%$ \\
SE 2000 & 2,10 & 2,10 & 0,00 & $-0,11 \%$ \\
S 2000 & 2,24 & 2,24 & 0,00 & $-0,13 \%$ \\
CO 2000 & 2,23 & 2,25 & $-0,02$ & $-1,10 \%$ \\
BR 2010 & 1,90 & 1,90 & 0,00 & $-0,10 \%$ \\
N 2010 & 2,45 & 2,47 & $-0,02$ & $-0,85 \%$ \\
NE 2010 & 2,05 & 2,06 & $-0,01$ & $-0,47 \%$ \\
SE 2010 & 1,71 & 1,70 & 0,01 & $0,46 \%$ \\
S 2010 & 1,79 & 1,78 & 0,01 & $0,42 \%$ \\
CO 2010 & 1,92 & 1,92 & 0,00 & $-0,01 \%$
\end{tabular}

Considerando a boa precisão da metodologia empregada no corte regional, é sustentável o exercício de desagregação por faixa de renda.

\subsection{NÍVEL E PADRÃO DA}

\section{FECUNDIDADE}

Além da tendência das Taxas de Fecundidade Total, importa verificar seu padrão etário, ou seja, como cada grupo etário quinquenal contribui para a taxa total.

O Gráfico 2 mostra os padrões etários da fecundidade nos anos de 2000 e 2010 e revela que foram os grupos mais jovens que registraram as maiores quedas da Taxa Específica de Fecundidade. Independentemente de qualquer juízo de valor sobre o nível das taxas, é positiva a redução no grupo entre 15 e 19 anos, uma vez que este grupo concentra riscos mais elevados para a saúde materno-infantil.

GRÁFICO 2: TAXAS ESPECÍFICAS DE FECUNDIDADE - BRASIL, 2000 E 2010

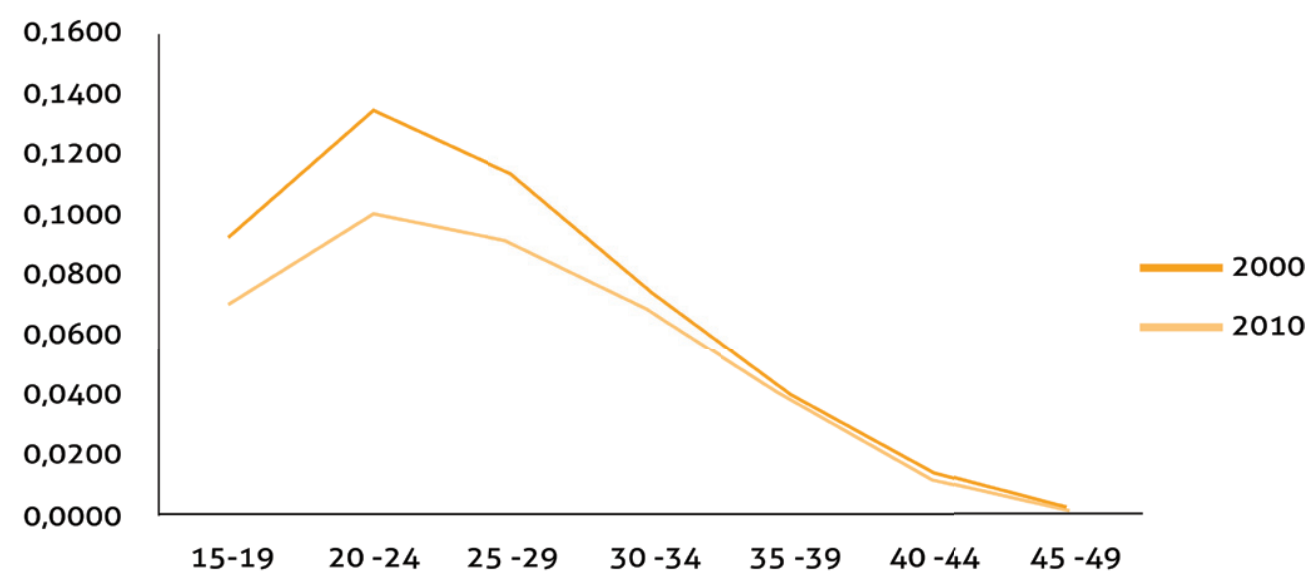

Fonte: Fundação IBGE - Censos de 2000 e 2010 - Elaboração do Autor. 


\subsection{DESAGREGAÇÃO DAS TAXAS DE FECUNDIDADE TOTAL POR FAIXA DE RENDA}

Ao contrário da desagregação por Grandes Regiões, ainda não se dispõe de todos os dados necessários ao cálculo da renda familiar per capita. Por esta razão, será utilizada a metodologia que subsidiou as simulações do Plano Brasil Sem Miséria, que considera a renda domiciliar per capita e dá tratamento específico às situações de renda zero (ou não declarada) que não são passíveis de cobertura pelo programa. Além disto, são segregadas da base de mulheres aquelas classificadas como pensionistas e/ou empregadas domésticas residentes e seus parentes e agregados, assim como as suas respectivas rendas. Tais mulheres constituem uma faixa de renda virtual ainda não passível de apuração, tendo sua fecundidade estimada para manter a inteireza dos dados e possibilitar a conferência da integridade dos resultados a partir de médias ponderadas.
Desta forma, as mulheres com idade entre 15 e 49 anos completos, moradoras de domicílios particulares permanentes, são classificadas em seis faixas de renda domiciliar per capita. Os limites destas faixas são, respectivamente, $R \$ 70,00, R \$ 140,00$, RS 255,00 e R\$ 1.020,00, em valores de 2010. Para o Censo de 2000, estes limites são deflacionados pelo Índice Nacional de Preços ao Consumidor (INPC), correspondendo ao menor limite o valor de $\mathrm{R} \$$ 35,63. As pensionistas e empregadas domésticas residentes compõem uma faixa adicional denominada "ignorada".

Uma vez classificadas as mulheres por faixa de renda domiciliar per capita, totalizam-se os respectivos números de filhos tidos nascidos vivos no último ano e no total da vida reprodutiva, e estimam-se as TFT pelo método descrito no item 1.1. Os resultados são representados no Gráfico 3.

\section{GRÁFICO 3: TAXAS DE FECUNDIDADE TOTAL POR FAIXA DE RENDA}

DOMICILIAR PER CAPITA. BRASIL, 2000 - 2010

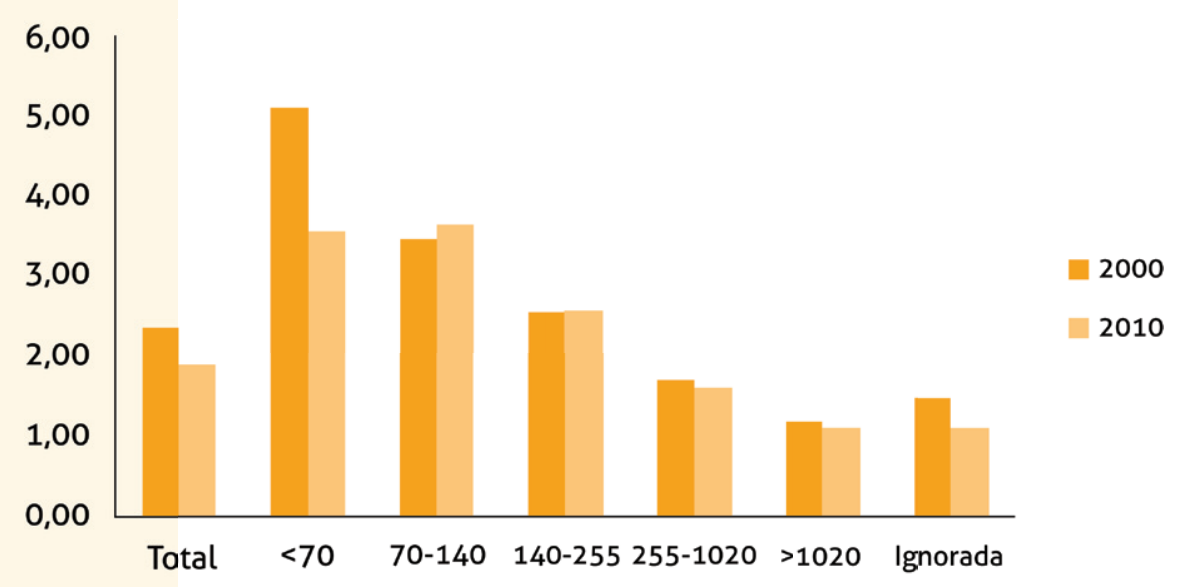


Os resultados são apresentados na Tabela 3, que compara as TFT por faixa de renda domiciliar per capita entre os Censos 2000 e 2010.

\section{TABELA 3: EVOLUÇÃO DA TAXAS DE FECUNDIDADE TOTAL POR FAIXA DE RENDA DOMICILIAR PER CAPITA}

\begin{tabular}{|c|c|c|c|c|}
\hline & 2000 & 2010 & $\begin{array}{c}\text { Variação } \\
\text { Filhos por } \\
\text { Mulher }\end{array}$ & $\begin{array}{c}\text { Variação } \\
\text { (\%) }\end{array}$ \\
\hline Total & 2,35 & 1,90 & $-0,46$ & $-19,35 \%$ \\
\hline$<70$ & 5,10 & 3,56 & $-1,54$ & $-30,19 \%$ \\
\hline $70-140$ & 3,47 & 3,64 & 0,17 & $4,98 \%$ \\
\hline $140-255$ & 2,55 & 2,56 & 0,01 & $0,48 \%$ \\
\hline $255-1020$ & 1,69 & 1,60 & $-0,09$ & $-5,43 \%$ \\
\hline >1020 & 1,17 & 1,11 & $-0,06$ & $-5,25 \%$ \\
\hline Ignorada & 1,47 & 1,11 & $-0,36$ & $-24,64 \%$ \\
\hline
\end{tabular}

Fonte: Fundação IBGE - Censos de 2000 e 2010 - Elaboração do Autor.

\begin{abstract}
A Tabela sugere que a primeira faixa de renda tenha sido a principal responsável pela acentuada queda da TFT no Brasil, enquanto a segunda faixa apresentou ligeiro crescimento. Há que se tratar esta assertiva com o devido cuidado, uma vez que houve no período expressiva transição de mulheres da primeira para a segunda faixa de renda domiciliar per capita ${ }^{14}$. Assim, parte da diferença de compor-
\end{abstract}

tamento poderia ser explicada pela transição de mulheres com muitos filhos da primeira para a segunda faixa.

Outra fonte de preocupação com a significância destes dados vem a ser a própria qualidade das informações sobre renda nos extratos inferiores e superiores, seja no Censo, seja nos demais registros administrativos. É possível imaginar uma grande quantidade de situações onde uma pequena variação na renda declarada implique em mudança de faixa, sobretudo entre as três primeiras. É, pois, temerário construir explicações mais sofisticadas a respeito da evolução das taxas.

\subsection{DESAGREGAÇÃO DAS TAXAS DE FECUNDIDADE TOTAL POR PERCEPÇÃO DE BENEFÍCIOS DE PROGRAMAS DE TRANSFERÊNCIA DE RENDA}

O Censo de 2010 incluiu uma pergunta específica sobre a percepção de benefícios de programas de transferência de renda, especialmente PBF e PETI. A comparação entre os grupos de mulheres com e sem PBF e/ou PETI pode ser feita classificando-se as mulheres moradoras de domicílios particulares permanentes por dois critérios. No primeiro consideram-se apenas

14 A análise das estimativas de fecundidade por corte de renda é tisnada pela inevitável fuga dos pressupostos do Método de Brass-Trussell ou de qualquer outro similar. Conforme descrito no item 3.2, estes métodos utilizam a relação entre o número total de filhos nascidos vivos e os nascidos vivos no último ano para corrigir falhas ou erros de declaração. Funcionam tanto melhor quanto mais fechada for a população de referência. No caso dos cortes por renda, ainda que não haja migração espacial, ocorre intensa transição de mulheres entre as classes definidas para efeito de comparação. Mulheres classificadas como "extremamente pobres", "demais pobres" ou "não pobres" na data de referência da pesquisa podem ter ingressado muito recentemente naquela faixa de renda domiciliar per capita, rompendo o suposto de continuidade. Desta forma, cada grupo em questão congregará muLheres que não pertenceram a ele por todo o período de até vinte anos, ou seja, a fecundidade estimada estará contaminada por padrões de fecundidade típicos das classes de origem das mulheres que se encontravam em cada classe na data de referência.

Revista Brasileira de Monitoramento e Avaliação | Número 3 | Janeiro-Junho de 2012

O Programa Bolsa Família tem efeito pro-natalista? Uma análise da fecundidade nos Censos 2000 e 2010 e das perspectivas a partir do Brasil Carinhoso. 
as que constam nos microdados como titulares do benefício. No segundo, consideram-se todas as que vivem em domicílios onde pelo menos um morador é titular do benefício. Em ambos os casos, são segregadas as pensionistas e/ou empregadas domésticas residentes.

O Gráfico 4 mostra os resultados das estimativas da TFT desagregadas pelo critério de percepção de PBF e/ou PETI no domicílio ${ }^{15}$.

Conforme se depreende do Gráfico 4, a Taxa de Fecundidade Total estimada para o grupo que percebe benefícios do PBF e/ou PETI é significativamente maior que a média geral, porém bastante semelhante às obtidas para as duas faixas de menor renda domiciliar per capita.

Longe de indicar um caráter pró-natalista dos benefícios em questão, as estimativas apresentadas prestam-se mais à constatação de que os benefícios são efetivamente destina- dos à parcela mais pobre da população, que historicamente ostenta taxas de fecundidade superiores à média nacional, embora fortemente declinantes.

Da mesma forma, são as mulheres com filhos que constituem o público-alvo primordial dos programas em questão. Assim, a percepção do benefício é decorrente da existência de filhos, especialmente nas faixas etárias mais baixas, e não estímulo à geração de filhos.

Em se tratando de uma política pública relativamente recente, ela já selecionou na origem mulheres com filhos ou com mais filhos que a média nacional. Trata-se de um fenômeno análogo à "seleção adversa"16, de larga utilização no mercado segurador. A relação entre titularidade do benefício e fecundidade não é de causa, e sim de efeito. Numa construção mais literária, o caráter do PBF e/ou PETI não seria pró-natalista, mas pós-natalista, inter-

\section{- GRÁFICO 4: TAXAS DE FECUNDIDADE TOTAL POR PERCEPÇÃO DE BENEFÍCIO DE BOLSA FAMÍLIA E/OU PETI}

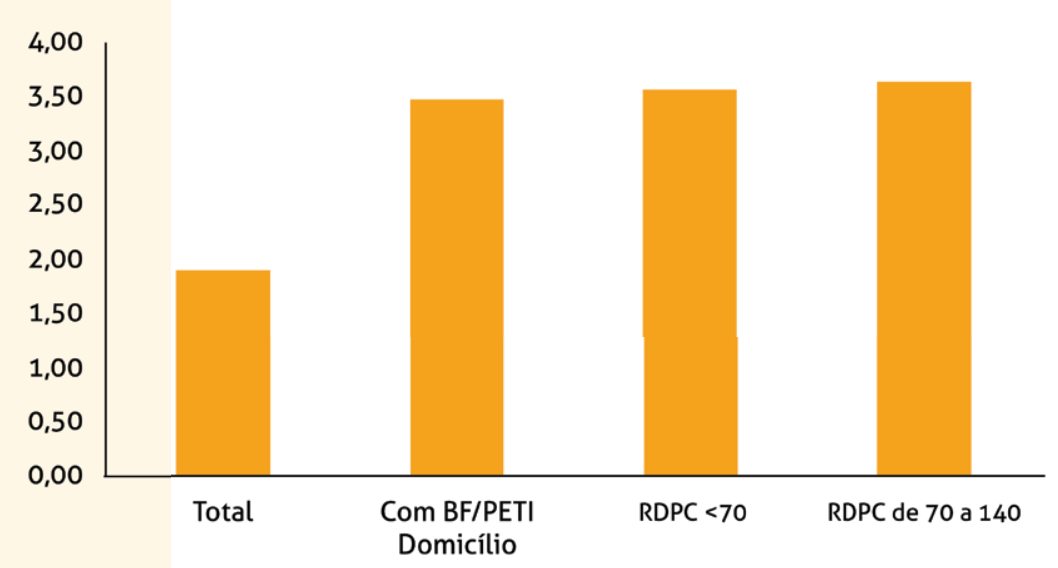


vindo sobre uma situação já constituída sem a indução prévia do Estado.

Como conclusão parcial, pode-se afirmar que os benefícios oferecidos pelo PBF e PETI não parecem ter interferido na tendência de redução da fecundidade da população-alvo, qual seja a parcela mais pobre da população.

\section{INOVAÇÕES NA ARǪUITETURA DO PROGRAMA DE BOLSA FAMÍLIA}

No mandato presidencial inaugurado em $1^{\circ}$ de janeiro de 2011, o governo federal vem intensificando as ações com vistas à superação da miséria ou da extrema pobreza. Termos oriundos do jargão militar, tais como "combate" e "erradicação", integram o discurso oficial, os nomes de ministérios e outros órgãos públicos.

A inovação mais radical introduzida no PBF foi a criação de um benefício familiar de valor variável, devido às famílias em que haja criança com idade de zero a seis anos, correspondente à diferença entre o total da renda familiar e o necessário para garantir uma renda per capita superior a R\$ 70,00, valor adotado como a linha de extrema pobreza no âmbito do Plano Brasil Sem Miséria. Este benefício foi introduzido pela Medida Provisória n 570, de 14 de maio de 2012, posteriormente convertida na Lei $n^{0} 12.722$, de 2012. O conjunto de medidas instituídas por essa lei ganhou o nome fantasia de "Brasil Carinhoso".

Seria este novo benefício um estímulo mais efetivo à fecundidade entre as mulheres mais pobres do país, à medida que o nascimento de uma criança pode representar um acréscimo de renda de até $\mathrm{R} \$ 70,00$ por membro da família? Numa situação extrema, de uma família sem renda habitual e composta por marido, mulher e quatro filhos com mais de seis anos, o nascimento de mais um filho habilitaria a família à percepção de um benefício de R\$ 490,00, valor bem maior que os tradicionalmente pagos pelo PBF.

Se já é dificílimo estimar a curva de demanda por um produto ou serviço em função do seu preço, pode-se argumentar que é totalmente impossível relacionar a demanda por novos filhos ao valor de um benefício

15 No caso do cortes por titularidade de benefício, também se observa fuga de pressupostos do Método de Brass - Trussell. Considerando que os programas só adquiriram escala apreciável a partir de 2004 e registraram forte aumento do número de beneficiários desde então, a maioria dos filhos nascidos vivos nasceu antes que a mãe fosse contemplada com o benefício.

16 Especialmente no ramo do Seguro Saúde, o cálculo dos prêmios deve levar em conta que a aquisição do direito ao atendimento estará sempre associada a uma maior propensão à utilização dos serviços. Por esta razão, as seguradoras sempre trabaLham com probabilidades de sinistro superiores à média de atendimento aos não segurados.

Revista Brasileira de Monitoramento e Avaliação | Número 3 | Janeiro-Junho de 2012

O Programa Bolsa Família tem efeito pro-natalista? Uma análise da fecundidade nos Censos 2000 e 2010 e das perspectivas a partir do Brasil Carinhoso. 
pecuniário oferecido por um programa do governo. É óbvio que as considerações envolvidas na decisão de ter ou não um filho vão muito além de qualquer equação econométrica, passando por fatores sociais, culturais, éticos e de saúde, em uma lista não extensiva.

De fato, seria de pouquíssima utilidade realizar uma pesquisa de campo e perguntar a uma amostra representativa do conjunto de mulheres quantas se disporiam a ter um ou mais de um filho conforme uma tabela de valores de benefícios. Muito provavelmente as respostas seriam quase unanimemente negativas, mas com baixíssima confiabilidade, persistindo a dúvida quanto ao efeito pró-natalista do programa.

O capítulo seguinte constitui uma tentativa de delimitar os contornos da questão sem adentrar em qualquer consideração quanto à propensão individual de qualquer mulher a ter um filho, ou mais de um filho, motivada pelos benefícios do programa.

\section{Da racionalidade à maternidade}

A negação dogmática de qualquer efeito pró-natalista do Programa Brasil Carinhoso é tão pouco científica quanto a sua afirmação. Por mais que se respeite a decisão autônoma das pessoas e por menos que se pretenda julgá-las à luz de qualquer parâmetro, a busca de respostas está na razão de ser de qualquer ci- ência, não sendo a Demografia uma exceção.

Admita-se que, da mesma forma que sempre houve regras e exceções, modas e extravagâncias nos comportamentos reprodutivos individuais, haverá um número indeterminado de mulheres propensas a ter um filho motivadas pelo programa.

Ainda que não se pretenda estimar uma curva de demanda por maternidade como função do valor do benefício, é possível analisar a propensão a ter filhos em função do programa utilizando a racionalidade econômica da decisão e a possibilidade concreta de sua implementação. Este exercício não leva à quantificação do efeito pró-natalista do programa, mas reduz em muito o espectro especulativo.

Admitindo-se que parte das mulheres aja com racionalidade econômica, impende investigar quantas dentre as existentes, com idade entre 15 e 49 anos, estariam expostas ao risco de decidir com base nessa racionalidade.

Uma vez que o benefício irá suplementar a renda familiar per capita até completar RS 70,00 por pessoa, apenas as mulheres enquadradas na faixa de renda abaixo deste valor poderiam vir a ter alguma vantagem financeira adicional proporcionada pelo programa caso tivessem mais um filho. Utilizando-se a renda per capita domiciliar (RPCD) como Proxy da renda per capita familiar, observamos que no Censo de 2010 este número era de 3.897.301 mulheres que tiveram 334.437 
filhos nos doze meses imediatamente anteriores à data de coleta, ou seja, 0,086 filhos por mulher no último ano. Seria esta a fecundidade base deste grupo de mulheres sob o impacto do PBF e sem o impacto do Programa Brasil Carinhoso.

Portanto, se todas resolvessem e conseguissem ter um filho no primeiro ano de funcionamento do programa, o número adicional de nascimentos chegaria a 3,563 milhões, maior que o total de nascidos vivos no mesmo período, que foi de 2,629 milhões. Estaríamos diante de uma onda enorme de nascimentos concentrados num único ano, que teria efeitos dramáticos sobre os sistemas de saúde e educação por pelo menos vinte anos, uma vez que geraria uma coorte mais que dobrada. Mas quão racional seria que isto ocorresse?

Conforme anteriormente dito, esta discussão só tem sentido se houver racionalidade econômica na decisão das mulheres ou das famílias pela maternidade. Admitindo-se que haja esta racionalidade, é razoável supor que ela afete diferentemente as mulheres conforme sua situação familiar. A Tabela 5 apresenta a classificação das mulheres com RPCD menor que R\$ 70,00 por mês, por grupo etário, existência de filhos e idade do fitho mais novo.

TABELA 5: MULHERES E FILHOS COM RENDA PER CAPITA DOMICILIAR ATÉ R\$ 70,OO SEGUNDO O CENSO 2010

\begin{tabular}{|c|c|c|c|c|c|c|c|c|}
\hline \multicolumn{9}{|c|}{ Grupo Etário } \\
\hline & $15-19$ & $20-24$ & $25-29$ & $30-34$ & $35-39$ & $40-44$ & $45-49$ & TOTAL \\
\hline Total de Mulheres & 780.612 & 634.673 & 618.269 & 584.259 & 494.174 & 424.584 & 360.800 & 3.897 .372 \\
\hline $\begin{array}{l}\text { Mulheres com } \\
\text { Filhos 0-6 anos }\end{array}$ & 157.369 & 389.044 & 423.342 & 311.710 & 183.209 & 98.471 & 37.793 & 1.600 .937 \\
\hline $\begin{array}{l}\text { Mulheres c/ Filho } \\
\text { mais novo } 6\end{array}$ & 608 & 12.621 & 36.040 & 39.451 & 26.257 & 16.904 & 9.497 & 141.377 \\
\hline Grupo de Risco & 623.244 & 245.629 & 194.927 & 272.550 & 310.966 & 326.113 & 323.007 & 2.296 .435 \\
\hline $\begin{array}{l}\text { Mulheres sem } \\
\text { Filhos }\end{array}$ & 622.609 & 230.294 & 105.030 & 60.053 & 42.462 & 37.391 & 33.802 & 1.131 .640 \\
\hline $\begin{array}{l}\text { Mulheres c/ Filho } \\
\text { mais novo > } 6\end{array}$ & 635 & 15.335 & 89.897 & 212.497 & 268.504 & 288.721 & 289.205 & 1.164 .795 \\
\hline
\end{tabular}

Fonte: Fundação IBGE - Censo 2010 - Elaboração do Autor

Revista Brasileira de Monitoramento e Avaliação | Número 3 | Janeiro-Junho de 2012

O Programa Bolsa Família tem efeito pro-natalista? Uma análise da fecundidade nos Censos 2000 e 2010 e das perspectivas a partir do Brasil Carinhoso. 
Supondo-se que o programa venha a atingir efetivamente todo o público-alvo, todas as mulheres cujo filho mais novo tenha menos de sete anos já estarão contempladas independentemente de novos nascimentos. Isto reduz o número de mulheres expostas ao risco de um acréscimo substancial de renda em caso de maternidade imediata em 1,6 milhões. Há que se tomar em separado o grupo de mulheres cujo filho mais novo já completou seis anos, para os quais o benefício do programa cessará quando este completar sete. Para este grupo, que soma 141.377 mulheres, pode-se pensar numa propensão à reposição como estratégia para evitar a perda de renda, mas este efeito tende a ser mitigado pela previsível elevação da idade de corte ao longo dos anos.

A previsibilidade do futuro aumento da idade de corte advém da aversão de qualquer governo ao trauma de uma agenda negativa. Depois do programa implantado, não é imaginá- vel que uma família tenha sua renda reduzida em, por exemplo, $\mathrm{R} \$ 400,00$ por mês apenas e tão somente porque o filho mais novo completou sete anos.

O grupo de risco compõe-se, portanto, por mulheres que não têm filhos e por aquelas cujo filho mais novo já completou sete anos. Conforme observa-se na tabela acima, são dois grupos de pouco mais de 1,1 milhão de mulheres em cada.

Para o grupo das mulheres sem filhos, o benefício proporcionado pelo nascimento de uma criança seria diretamente proporcional ao número de membros do grupo familiar. A Tabela 6 mostra a divisão das mulheres sem filhos por grupo etário quinquenal e por número de moradores do domicílio, tomado como Proxy do grupo familiar. A última coluna mostra o valor do benefício máximo proporcionado pelo nascimento de uma criança, supondo-se que a família não receba PBF.

TABELA 6: MULHERES COM RENDA PER CAPITA DOMICILIAR ATÉ RS 70,00, SEM FILHOS, POR GRUPO ETÁRIO, NÚMERO DE MORADORES NO DOMICÍLIO E BENEFÍCIO MÁXIMO NO BRASIL CARINHOSO

\begin{tabular}{crrrrrrrrr} 
Moradores & \multicolumn{10}{c}{ Grupo Etário } \\
Domicílio & \multicolumn{1}{c}{$15-19$} & $20-24$ & $25-29$ & \multicolumn{1}{c}{$30-34$} & $35-39$ & $40-44$ & $45-49$ & \multicolumn{1}{c}{ TOTAL } & \multicolumn{1}{c}{ Máximo } \\
1 & 3.058 & 5.361 & 4.864 & 3.889 & 3.193 & 3.579 & 4.317 & 28.260 & 140,00 \\
2 & 50.462 & 43.450 & 26.634 & 15.647 & 12.418 & 11.845 & 11.635 & 172.092 & 210,00 \\
3 & 64.584 & 28.463 & 13.997 & 8.723 & 6.279 & 5.346 & 5.998 & 133.391 & 280,00 \\
4 & 110.040 & 33.815 & 14.747 & 8.370 & 5.440 & 4.874 & 3.581 & 180.865 & 350,00 \\
5 & 113.343 & 32.526 & 12.013 & 7.120 & 5.019 & 3.784 & 2.765 & 176.569 & 420,00 \\
6 & 85.786 & 24.479 & 8.679 & 4.908 & 2.795 & 2.512 & 1.659 & 130.817 & 490,00 \\
7 & 60.954 & 16.996 & 6.053 & 2.645 & 2.103 & 1.380 & 875 & 91.005 & 560,00 \\
8 & 48.162 & 14.432 & 5.714 & 2.858 & 1.839 & 1.321 & 1.089 & 75.415 & 630,00 \\
9 & 86.221 & 30.773 & 12.330 & 5.893 & 3.376 & 2.751 & 1.882 & 143.225 & 700,00 \\
& 622.609 & 230.294 & 105.030 & 60.053 & 42.462 & 37.391 & 33.802 & 1.131 .640 &
\end{tabular}


Como se observa, há uma forte concentração de mulheres jovens, especialmente adolescentes, no grupo de risco. São mulheres que tendem a ter filhos em algum momento no futuro. Poderiam antecipar este momento com o objetivo de usufruir dos benefícios da ação Brasil Carinhoso? O capítulo final deste artigo elenca algumas razões para se acreditar que não.
Prosseguindo na decomposição do grupo de risco, impende analisar o conjunto das mulheres que têm filhos, mas cujo filho mais novo já tem mais de seis anos. A Tabela 7 apresenta a classificação daquelas mulheres por grupo etário e número de moradores no domicílio.

TABELA 7: MULHERES COM RENDA PER CAPITA DOMICILIAR DE ATÉ RS 70,OO, COM FILHO MAIS NOVO DE MAIS DE SEIS ANOS, POR GRUPO ETÁRIO E NÚMERO DE MORADORES NO DOMICÍLIO

\begin{tabular}{lrrrrrrrrr} 
Moradores & \multicolumn{1}{c}{ Grupo Etário } & & \multicolumn{2}{c}{ Benefício } \\
no Domicílio & $15-19$ & $20-24$ & $25-29$ & $30-34$ & $35-39$ & $40-44$ & $45-49$ & TOTAL & Máximo \\
1 & 8 & 172 & 746 & 1.779 & 2.760 & 6.001 & 10.316 & 21.781 & 140,00 \\
2 & 51 & 1.932 & 8.986 & 16.756 & 22.295 & 34.817 & 48.779 & 133.618 & 210,00 \\
3 & 144 & 5.296 & 28.255 & 45.021 & 51.782 & 61.289 & 62.525 & 254.312 & 280,00 \\
4 & 139 & 3.145 & 24.463 & 62.414 & 75.312 & 69.262 & 57.632 & 292.363 & 350,00 \\
5 & 81 & 1.677 & 13.877 & 46.978 & 56.581 & 50.334 & 40.684 & 210.210 & 420,00 \\
6 & 56 & 877 & 5.918 & 21.182 & 29.078 & 29.282 & 25.817 & 112.211 & 490,00 \\
7 & 1 & 527 & 2.710 & 8.631 & 14.260 & 15.785 & 16.412 & 58.325 & 560,00 \\
8 & 44 & 422 & 1.791 & 4.706 & 7.785 & 9.703 & 10.949 & 35.400 & 630,00 \\
9 & 112 & 1.288 & 3.151 & 5.028 & 8.655 & 12.247 & 16.089 & 46.573 & 700,00
\end{tabular}

Fonte: Fundação IBGE - Censo 2010 - Elaboração do Autor.

Como se observa, predominam neste grupo mulheres com trinta anos ou mais de idade, sendo que mais da metade delas têm pelo menos quarenta anos. É óbvio que a racionalidade destas mulheres é diferente da das mais jovens, assim como sua capacidade biológica de implementar a decisão de ter mais um filho.

Apesar das clamorosas lacunas no conhecimento sobre os métodos contraceptivos utilizados pelas mulheres brasileiras, especialmente as do grupo de risco, o padrão etário da fecundidade observado entre as mulheres mais pobres sugere uma alta incidência de esterilização cirúrgica, virtualmente irreversível, entre as mulheres a partir dos trinta anos. Desta forma, é de todo plausível supor que muitas das mulheres classificadas neste subgrupo tenham se submetido à esterilização, estando, portanto, excluídas do risco. Em que pese o avanço e a crescente popularização dos métodos de reprodução assistida, eles não estão ao alcance das mulheres nesta faixa de renda.

Revista Brasileira de Monitoramento e Avaliação | Número 3 | Janeiro-Junho de 2012

O Programa Bolsa Família tem efeito pro-natalista? Uma análise da fecundidade nos Censos 2000 e 2010 e das perspectivas a partir do Brasil Carinhoso. 


\section{GRÁFICO 6: PADRÃO ETÁRIO DA FECUNDIDADE DAS MULHERES COM RDPC DE ATÉ R\$ 70,00 EM 2010}

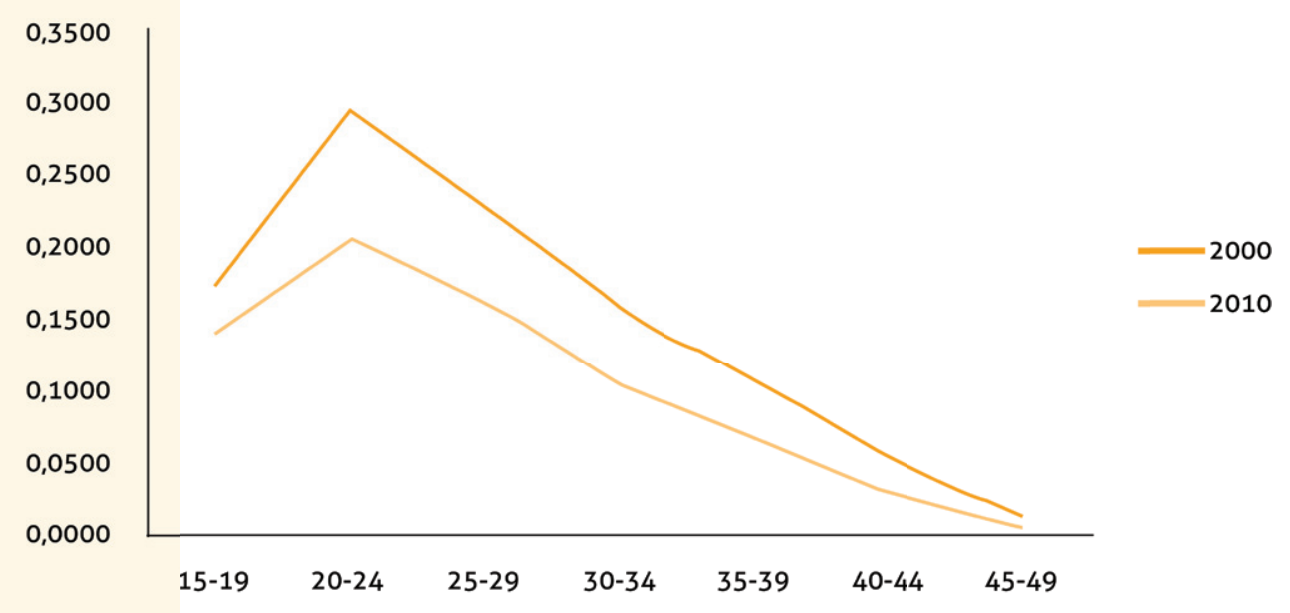

Fonte: Fundação IBGE - Censos de 2000 e 2010 - Elaboração do Autor.

\section{Razões para se duvidar do efeito pró- natalista da ação Brasil Carinhoso}

Ao longo deste artigo, procurou-se analisar a possibilidade da ação Brasil Carinhoso vir a ter efeitos pró-natalistas, decompondo-se o grupo de mulheres em idade reprodutiva conforme sua exposição ao risco da decisão racional pela maternidade motivada pela atratividade dos benefícios do programa. Este exercício delimitou dois subgrupos de risco entre as mulheres com idade entre 15 e 49 anos e renda per capita domiciliar abaixo de R\$ 70,00 em 2010, quais sejam o das mulheres sem filhos e o daquelas cujo filho mais novo já tem mais de seis anos, e quantificou cada um deles em pouco mais de 1,1 milhão de mulheres, dentre as 53 milhões existentes no país naquele grupo etário.
Uma vez que os subgrupos de risco foram delimitados e estratificados pelas variáveis de idade, número de moradores no domicílio e total de filhos nascidos vivos, chegou-se a números ainda menores de mulheres expostas ao risco.

No caso daquelas que têm filhos e não tiveram nenhum nos seis anos anteriores ao Censo de 2010, o universo efetivamente exposto ao risco será reduzido de forma proporcional à incidência de esterilizações cirúrgicas já realizadas, número este presumivelmente alto, embora não mensurado.

Desta forma, o subgrupo efetivamente exposto ao risco resume-se ao das mulheres sem 
filhos, que muito provavelmente virão a tê-los ao longo dos próximos anos e poderiam antecipar sua ocorrência.

Mais da metade deste grupo tinha entre 15 e 19 anos no ano 2010. Trata-se do grupo menos susceptível à racionalidade econômica e mais exposto à diversidade de estímulos de consumo alternativo, tanto de recursos disponíveis quanto de tempo. Imaginar um número expressivo de adolescentes decidindo engravidar para proporcionar um benefício financeiro à família chega a ser quase um delírio, mas, admitindo-se a hipótese para fins de raciocínio, vislumbram-se dois óbices decorrentes desta mesma racionalidade.

O primeiro é o lapso de tempo entre a decisão pela maternidade e o nascimento da criança. Entre engravidar e dar à luz são necessários nove meses, nos quais as despesas aumentam muito e não há criança para iniciar o processo de habilitação ao benefício. Além disso, mesmo entre as mulheres unidas a um parceiro, o que não é certamente o caso da maioria neste grupo etário, a probabilidade de gravidez não vai além de 10\% em cada ciclo menstrual, aproximadamente mensal.

O segundo óbice tem a ver com a própria credibilidade do programa entre a população-alvo. Uma vez imputada às mulheres uma racionalidade econômica forte o bastante para levá-las a decidir ter um filho em troca de um benefício, há que se considerar que esta decisão leve em conta a certeza da percepção do benefício.

O PBF, que existe desde 2004, intenta beneficiar as famílias mais pobres em cada município do País. Ocorre que na vida real a identificação dos efetivamente mais pobres é um desafio ainda não vencido pela administração. A despeito de todos os indicadores positivos do programa, o cruzamento das informações de renda per capita domiciliar com percepção de benefícios no Censo de 2010 revela significativas deficiências de cobertura entre o público-alvo do Brasil Carinhoso. A Tabela 8 ilustra este quadro, quanto à participação relativa de mulheres não beneficiárias frente ao total de cada faixa de renda por Grandes Regiões.

TABELA 8: PARTICIPAÇÃO RELATIVA DE PESSOAS POBRES SEM BENEFÍCIOS DO PBF E/OU PETI POR REGIÃO ENTRE OS EXTREMAMENTE POBRES E DEMAIS POBRES POR REGIÃO - CENSO 2010

$\begin{array}{lcc} & \text { Renda per capita domiciliar até R\$ } 70,00 & \text { Renda per capita domiciliar de R\$ } 70,00 \text { a } R \$ 140,00 \\ \text { BR } & 40,92 \% & 42,33 \% \\ \text { N } & 49,92 \% & 44,25 \% \\ \text { NE } & 28,85 \% & 32,44 \% \\ \text { SE } & 61,99 \% & 57,42 \% \\ \text { S } & 57,96 \% & 49,34 \% \\ \text { CO } & 64,63 \% & 55,09 \%\end{array}$

Fonte: Fundação IBGE - Censo 2010 - Elaboração do Autor.

Revista Brasileira de Monitoramento e Avaliação | Número 3 | Janeiro-Junho de 2012

O Programa Bolsa Familia tem efeito pro-natalista? Uma análise da fecundidade nos Censos 2000 e 2010 e das perspectivas a partir do Brasil Carinhoso. 
Como se observa, $41 \%$ dos extremamente pobres e $42 \%$ dos demais pobres não foram declarados no Censo de 2010 como beneficiários diretos ou indiretos do PBF e PETI. Estes percentuais são ainda maiores nas regiões Sudeste, Sul e Centro-Oeste, chegando a mais de dois terços nas situações extremas, como no Estado de São Paulo e no Distrito Federal. É de se esperar, portanto, que muIheres eventualmente dispostas a engravidar motivadas pelo benefício do Brasil Carinhoso abstenham-se de fazê-lo se suas famílias não estão recebendo PBF, apesar de preencherem os requisitos.

Quanto àquelas cuja família já está recebendo PBF, o benefício adicional do Brasil Carinhoso será significativamente menor que o máximo estimado nas tabelas 6 e 7, relativizando a vantagem econômica de uma gravidez.

Em face de todo o exposto, fica patente que o impacto pró-natalista do Programa Brasil Carinhoso tende a ser tão pouco significativo quanto foi o do PBF, resumindo-se a, no máximo, algumas poucas antecipações de nascimentos esperados para os próximos anos, antecipações estas posteriormente compensadas na série histórica futura.

\section{Missão cumprida, sem baixas?}

Este artigo procurou enfrentar o debate sobre efeitos pró-natalistas da ação Brasil Carinhoso à luz da própria racionalidade econômica que importantes formadores de opinião pretendem imputar às mulheres mais pobres do
País e ofereceu elementos para denegar a sua probabilidade.

Entretanto, isto não significa que o programa não esteja fadado a enfrentar desafios além das possibilidades dos órgãos responsáveis.

O primeiro desses desafios é o de identificar corretamente as famílias efetivamente mais pobres do país, para que o benefício desenhado para erradicar instantaneamente a extrema pobreza entre as crianças de zero a seis anos seja pago às famílias certas. A virtual impossibilidade de se comprovar a ausência de renda coloca as autoridades responsáveis pelo cadastramento e pela concessão e manutenção dos benefícios na ingrata posição de escolher os "pobres mais pobres entre os mais pobres", sem que seja possível abstrair alguma subjetividade nos procedimentos. A soma das falhas nestes procedimentos explica parcialmente os números mostrados na Tabela 8, e conspira para que continue existindo extrema pobreza a despeito de todos os esforços para erradicá-la.

O segundo desafio vem a ser o previsível aumento do estímulo à subdeclaração de renda, no intuito de enquadrar-se nos requisitos do programa. Uma vez que a imensa maioria da população-alvo do programa encontra-se no setor informal da economia, sem qualquer fonte de renda verificável de forma não testemunhal, há mais racionalidade econômica em uma mudança de declaração de renda para baixo que na produção de um filho com objetivo de fazer jus ao benefício. 
Este fenômeno, cujo enfrentamento eficaz custaria várias vezes o valor total do programa, pode vir a produzir fortes dissabores aos responsáveis pela formulação e implementação da ação Brasil Carinhoso. Uma ação governamental com o nobre propósito de erradicar a extrema pobreza na primeira infância, se submetida a restrições orçamentárias que façam valer os limites de gastos informados na Exposição de Motivos que originou a ação, da ordem de R\$ 2,3 bilhões por ano, poderá produzir um inusitado aumento do número de pessoas autodeclaradas extremamente pobres, pela via da "migração de retorno" de milhões de famílias que recém atravessaram a linha de extrema pobreza.

Estes desafios são muito maiores, mais importantes e mais difíceis na condução do programa que a discussão sobre impactos pró-natalistas entre os mais pobres.

\section{Revoluções por minuto}

Depois de concluída a revisão "final" deste artigo, foi editada a Medida Provisória no 590, de 29 de novembro de 2012, que alterou as regras da ação Brasil Carinhoso, estendendo o benefício variável suficiente para o usufruto de uma renda per capita familiar de $\mathrm{R} \$$ 70,00 a todas as famílias com filhos de até quinze anos de idade ${ }^{17}$.

A medida exclui do grupo de mulheres expostas ao risco de decidir racionalmente ter mais um filho, motivadas pelos benefícios do programa, todas aquelas que têm filhos e cujo filho mais novo tenha menos de dezesseis anos. Desta forma, além das mulheres que não têm filhos, o grupo de risco fica limitado a 315.405 mulheres, das quais 263.918 já têm pelo menos quarenta anos e 156.098 já têm pelo menos 45 anos. Na prática, o grupo de risco fica reduzido apenas e tão somente às mulheres que ainda não têm filhos e muito provavelmente virão a tê-los nos próximos quinze anos, independentemente de estímulo financeiro oficial.

Em suma, os impactos do PBF e seus sucedâneos sobre as tendências da fecundidade entre a população mais pobre são de pequena monta, pelo menos se analisados sobre o prisma da racionalidade econômica.

17 Esta iniciativa altera profundamente as características do PBF, tanto no que concerne aos valores dos benefícios pagos quanto no que diz respeito às condicionalidades para manutenção dos benefícios por parte das famílias beneficiárias. Uma vez mais, a análise apresentada neste artigo cingir-se-á aos aspectos ligados à fecundidade.

Revista Brasileira de Monitoramento e Avaliação | Número 3 | Janeiro-Junho de 2012 


\section{Referências bibliográficas}

ARIÈS, P. Two successive motivations for the declining birth rates in the west. In: HÖHN, C.; MACKENSEN, R. (Ed.). Determinants of fertility trends: theories re-examined. Population and Development Review, New York, v.6, n.4, p.645650, 1980.

BERQUUÓ, E.; CAVENAGHI, S. Mapeamento sócio-econômico e demográfico dos regimes de fecundidade no Brasil e sua variação entre 1991 e 2000. In: ENCONTRO NACIONAL DE ESTUDOS POPULACIONAIS, 14., 2004, Caxambu. Anais... Belo Horizonte: ABEP, 2004.

BORGEOIS-PICHAT, J. The Unprecedented Shortage of Births in Europe. Population and Development Review - A Supplement to Volume 12, 1986.

CARVALHO, J. A. M. Para onde iremos: algumas tendências populacionais no século XXI. Revista Brasileira de Estudos de População, São Paulo, v.18, n.1/2, p.7-13, jan./dez. 2001.
CHESNAIS, J. C. Fertility, family, and social policy in Contemporary Western Europe. Population and Development Review, New York, v.22, n.4, p.729-739, dec.1996.

La theorie originelle de la transition demographique: validite et liuites du modeles. $1986 a$

La transition démographique: étapes, formes, implications économiques: etude de séries temporelles (1720-1984) relatives à 67 pays. Population, New York, v.41, n.6, p.10591070, nov./dec.,1986b.

CLIOUET, R. L. La deuxième transition démographique: réalité ou fiction? Council of Europe, Études demographiques, n.23, 1991.

COLEMAN, D. Why we don't have to believe without doubting in the 'Second Demographic Transition': some agnostic comments. Population and Development Review, New York, v.32, n.3, 2004. 
COLEMAN, David Immigration and Ethnic Change in Low-Fertility Countries: A Third Demographic Transition, POPULATION AND DEVELOPMENT REVIEW, v. 32, n.3.

FARIA, V. E. Políticas de Governo e regulação da fecundidade: consequências não antecipadas e efeitos perversos. Ciências Sociais Hoje. São Paulo: Vértice/ANPOCS, 1989.

FUNDAÇÃO IBGE. Censo Demográfico 2010. Rio de Janeiro, 2010. ro, 2000 .

Censo Demográfico 2000. Rio de Janei-

Censo Demográfico 2010. Rio de Janeiro, 2010.

LESTHAEGHE, R.; SURKYN, J. When history moves on: the foundation and diffusion of a second demographic transition in western countries: an interpretation. In: BIENNIAL CONFERENCE OF THE AUSTRALIAN POPULATION ASSOCIATION, 12., 2004, Australia. Anais ... Australia: Australian Population Association, 2004.
MCDONALD, P. Gender equity, social institutions and the future of fertility. In: COSIO-ZAVALA, M. $E$. Women and families: evolution of the status of women as a factor and consequence of changes in family dynamics. Paris: CICRED/UNFPA/ UNESCO, 1997.

MERRICK, T.; BEROUÓ, E. The determinants of Brazil's recent rapid decline in fertility. Washington: National Academies Press, 1983. (Report, $n^{\circ} 23$ ).

PAIVA, P. T. A. The process of proletarianization and fertility transicion in Brazil. , Belo Horizonte, CEDEPLAR, 1984. (Texto para Discussão, $n^{\circ} 15$ ).

PATARRA, N. L. Transición demográfica: resumen histórico o teoria de población. Demografia y Economia, México, v.3, n.1, p.86-95, 1973.

THERBORN, G. Casais, bebês e estados. In: Sexo e poder: a família no mundo, 1900-2000. São Paulo: Contexto, 2006.

Revista Brasileira de Monitoramento e Avaliação | Número 3 | Janeiro-Junho de 2012

O Programa Bolsa Família tem efeito pro-natalista? Uma análise da fecundidade nos Censos 2000 e 2010 e das perspectivas a partir do Brasil Carinhoso. 